\title{
Genetic parameters for female fertility, locomotion, body condition score, and linear type traits in Czech Holstein cattle
}

\author{
V. Zink, ${ }^{\star 1}$ M. Štípková, ${ }^{*}$ and J. Lassen† \\ *Department of Cattle Breeding, Institute of Animal Science, Přátelství 815, 10400 Prague 10 - Uhř́něves, Czech Republic \\ †Department of Genetics and Biotechnology, Danish Institute of Agricultural Sciences, Aarhus University, PO Box 50, DK-8830 Tjele, Denmark
}

\begin{abstract}
The aim of this study was to estimate genetic parameters for fertility traits and linear type traits in the Czech Holstein dairy cattle population. Phenotypic data regarding 12 linear type traits, measured in first lactation, and 3 fertility traits, measured in each of first and second lactation, were collected from 2005 to 2009 in the progeny testing program of the Czech-Moravian Breeders Corporation. The number of animals for each linear type trait was 59,467, except for locomotion, where 53,436 animals were recorded. The 3 -generation pedigree file included 164,125 animals. (Co)variance components were estimated using AI-REML in a series of bivariate analyses, which were implemented via the DMU package. Fertility traits included days from calving to first service (CF1), days open (DO1), and days from first to last service (FL1) in first lactation, and days from calving to first service (CF2), days open (DO2), and days from first to last service (FL2) in second lactation. The number of animals with fertility data varied between traits and ranged from 18,915 to 58,686 . All heritability estimates for reproduction traits were low, ranging from 0.02 to 0.04 . Heritability estimates for linear type traits ranged from 0.03 for locomotion to 0.39 for stature. Estimated genetic correlations between fertility traits and linear type traits were generally neutral or positive, whereas genetic correlations between body condition score and CF1, DO1, FL1, CF2 and DO2 were mostly negative, with the greatest correlation between BCS and CF2 (-0.51). Genetic correlations with locomotion were greatest for CF1 and CF2 ( -0.34 for both). Cows that are genetically extreme for angularity, stature, and body depth tend to perform poorly for fertility traits. At the same time, cows that are genetically predisposed for low body condition score or high locomotion score are generally inferior in fertility.
\end{abstract}

Received July 23, 2010.

Accepted June 15, 2011.

${ }^{1}$ Corresponding author: vzink@seznam.cz
Key words: fertility, locomotion, linear type trait, body condition score

\section{INTRODUCTION}

Worldwide, poor reproductive performance is a huge economic burden on the dairy cattle industry. Increases in milk production due to genetic selection tend to cause higher risk of culling, due to a greater incidence of reproductive disorders and poorer reproductive performance (Holtsmark et al., 2008). Reproduction traits are usually unfavorably genetically correlated with milk production traits (Windig et al., 2006). Direct selection for fertility traits is typically inefficient due to low heritability of these traits. This is often due to a high environmental variance for fertility traits, which makes it hard to distinguish good genotypes from bad, even though the additive genetic variance is often high for fertility traits. An alternative way to improve fertility could be through selection for linear type traits that are favorably correlated with reproductive traits. Cows with poor locomotion tend to have a longer period of negative energy balance (Collard et al., 2000), which can affect reproduction. It is known that poor feet and legs are associated with higher risk of culling (Sewalem et al., 2005); on the contrary, higher scores for feet and leg traits are positively correlated with functional traits such as fertility (Pérez-Cabal et al., 2006). At the beginning of lactation, cows are in negative energy balance due to a rapid increase in milk production, coupled with insufficient DMI. The aim of farmers is to maximize feed intake while decreasing the risk of a negative energy balance. Negative energy balance affects a cow's ability to show a strong visual heat and her ability to conceive when inseminated. Changes in BCS, especially when due to metabolic changes at the beginning of lactation, can also influence fertility (Oikonomou et al., 2008). Like in many other countries, BCS is routinely measured in the Czech Republic as part of the linear type classification program, because it can be used routinely in dairy herds as a management tool (Edmonson et al., 1989). The BCS at calving, as well as the change in BCS during early lactation, are important factors 
Table 1. Basic statistics for reproduction traits in this study, including number of records (N), mean, standard deviation, minimum (Min.), maximum (Max.), heritability $\left(\mathrm{h}^{2}\right)$, and standard error

\begin{tabular}{lcrrrrl}
\hline Trait $^{1}$ & $\mathrm{~N}$ & Mean & SD & Min. & Max. & $\mathrm{h}^{2} \pm \mathrm{SE}$ \\
\hline CF1 & 58,686 & 80.9 & 29.2 & 21 & 180 & $0.04 \pm 0.01$ \\
DO1 & 53,026 & 113.9 & 46.1 & 40 & 220 & $0.04 \pm 0.01$ \\
FL1 & 52,632 & 34.3 & 41.8 & 0 & 187 & $0.03 \pm 0.004$ \\
CF2 & 25,473 & 78.8 & 27.1 & 21 & 180 & $0.04 \pm 0.01$ \\
DO2 & 19,093 & 116.2 & 46.5 & 40 & 220 & $0.02 \pm 0.01$ \\
FL2 & 18,915 & 38.7 & 43.6 & 0 & 189 & $0.03 \pm 0.01$ \\
\hline
\end{tabular}

${ }^{1} \mathrm{CF}=$ days from calving to first insemination; $\mathrm{DO}=$ days open; $\mathrm{FL}=$ days from first to last insemination; 1 refers to first parity and 2 refers to second parity.

with respect to a cow's ability to conceive (Roche et al., 2009). In addition, losses in BCS at the beginning of lactation are associated with greater days to first service (Dechow et al., 2002). Although many measures of reproductive performance exist, days from calving to first service $(\mathbf{C F})$, days open (DO), and days from first to last service (FL) are among the more common traits for assessing fertility in dairy herds. Whereas CF represents a cow's ability to resume cycling after calving and show visual heat, DO and FL tend to indicate a cow's ability to conceive. The aim of this study was to estimate genetic parameters for linear type traits, including BCS and locomotion, and measures of female fertility in the Czech Holstein population.

\section{MATERIALS AND METHODS}

\section{Data}

Phenotypic data for linear type and fertility traits were obtained from the official progeny testing database of the Czech-Moravian Breeders Corporation (Prague, Czech Republic). These data were from cows that were classified from October 2005 to February 2009. Only data from first-parity cows that were classified between 30 and $210 \mathrm{~d}$ postpartum were used. The total number of animals with linear type data was 59,467, whereas the number of animals with linear type and locomotion data was 53,436 . The number of herds with fertility data was 936, and the number of records for fertility varied widely between traits, ranging from 58,686 to 18,915 . Fertility data for CF were collected in the interval between 21 and $180 \mathrm{~d}$ postpartum, whereas fertility data for DO were collected between 40 and $220 \mathrm{~d}$ postpartum. These intervals were chosen to represent reproduction strategies in commercial herds. A summary of the data are presented in Table 1 . The 3 -generation pedigree contained 164,125 animals. In the Czech Republic, linear type traits are scored on a 1 to 9 scale, according to the official methods based on the World Holstein Friesian Federation (WHFF) guidelines (http://www.whff.info/info/typetraits.php).
Two additional linear type traits, udder width and bone quality, are assessed in Czech Holsteins, and the latter trait was included in this study. All linear type traits, including BCS, are evaluated between 30 and $210 \mathrm{~d}$ postpartum in primiparous cows. In the present study, 12 traits were considered: stature, chest width, body depth, angularity, rump angle, rump width, rear legs rear view, rear legs set, foot angle, bone quality, locomotion, and BCS.

\section{Estimation of Genetic Parameters}

Variance components were estimated in a series of bivariate animal models using 3 generations of pedigree information. Heritability estimates and their standard errors for each trait were calculated as an average of 6 estimates for linear type traits and 12 estimates for reproduction traits, because this corresponds to the number of bivariate analyses that were performed for each trait.

For conformation traits, the model was of the following form:

$$
\begin{aligned}
& y_{i j k l m}=h_{i}+z_{j}+s_{k}+c_{l}+\alpha \times d_{i j k l m} \\
& +\beta \times a a c_{i j k l m}+\delta \times a a c_{i j k l m}^{2}+a_{m}+e_{i j k l m},
\end{aligned}
$$

where $h_{i}$ is the fixed effect of herd of calving $i(i=1$, . $\ldots, 936), z_{j}$ is the fixed effect of year of calving $j(j=1$, $\ldots, 7), s_{k}$ is the fixed effect of season of calving $k(k=$ $1, \ldots, 4)$ starting in January each year, and $c_{l}$ is the fixed effect of classifier $l(l=1, \ldots, 7)$. Days in milk at classification $\left(d_{i j k l m}\right)$, age at calving $\left(a a c_{i j k l m}\right)$, and age at calving squared $\left(a a c_{i j k l m}^{2}\right)$ are fixed regressions, and $\alpha$, $\beta$, and $\delta$ are regression coefficients. Finally, $a_{m}$ is the random animal effect and $e_{i j k l m}$ is the random residual effect.

For fertility traits, the model contained the following effects:

$y_{i j k l m}=h_{i}+z_{j}+s_{k}+\alpha \times a a c_{i j k l m}+\beta \times a a c_{i j k l m}^{2}+a_{m}+e_{i j k l m}$, 
where $h_{i}$ is the fixed effect of herd of calving $i(i=1$, . $\ldots, 936), z_{j}$ is the fixed effect of year of calving $j(j=$

$1, \ldots, 7)$, and $s_{k}$ is the fixed effect of season of calving $k(k=1, \ldots, 4)$. Age at calving $\left(a a c_{i j k l m}\right)$ and age at calving squared $\left(a a c_{i j k l m}^{2}\right)$ are fixed regressions with regression coefficients $\alpha$ and $\beta$. Finally, $a_{m}$ is the random animal effect and $e_{i j k l m}$ is the random residual effect.

The vector of additive genetic effects (a) was assumed to be $\mathrm{N}\left(0, \mathbf{A} \boldsymbol{\sigma}_{\mathrm{a}}^{2}\right)$, where $\mathbf{A}$ is the additive genetic relationship matrix. The vector of residual effects (e) was assumed to be $\mathrm{N}\left(0, \mathbf{I} \boldsymbol{\sigma}_{\mathrm{e}}^{2}\right)$, and $\operatorname{cov}(\mathbf{a}, \mathbf{e})=\mathbf{0}$.

The (co)variance structure among vectors of random variables in the bivariate model was

$$
\operatorname{var}\left[\begin{array}{c}
a_{1} \\
a_{2} \\
e_{1} \\
e_{2}
\end{array}\right]=\left[\begin{array}{cccc}
\mathbf{A} \boldsymbol{\sigma}_{\mathrm{a} 1}^{2} & \mathbf{A} \boldsymbol{\sigma}_{\mathrm{a} 12} & \mathbf{0} & \mathbf{0} \\
\mathbf{A} \boldsymbol{\sigma}_{\mathrm{a} 21} & \mathbf{A} \boldsymbol{\sigma}_{\mathbf{a} 2}^{2} & \mathbf{0} & \mathbf{0} \\
\mathbf{0} & \mathbf{0} & \mathbf{I} \boldsymbol{\sigma}_{\mathbf{e} 1}^{2} & \mathbf{I} \boldsymbol{\sigma}_{\mathrm{e} 12} \\
\mathbf{0} & \mathbf{0} & \mathbf{I} \boldsymbol{\sigma}_{\mathrm{e} 21} & \mathbf{I} \boldsymbol{\sigma}_{\mathbf{e} 2}^{2}
\end{array}\right] .
$$

Variance components were analyzed using an AI-REML algorithm (Jensen et al., 1997), implemented in the DMU package (Madsen and Jensen, 2008).

\section{RESULTS}

The descriptive statistics for fertility and linear type traits are presented in Table 1 and Table 2, respectively. The number of animals differs between first and second lactation, mainly because of a high culling rate of first-parity cows in the Czech Holstein population. The number of animals for locomotion was less than for linear type traits, because only animals that have no injury or disability that could influence the classification are assessed for locomotion. Animals that have problems related to feet and leg traits are classified for all traits except locomotion. The fertility traits show similar means within trait group across lactations, and the relatively poor values for these traits select the high incidence of reproductive problems in Czech Holstein herds and the high risk of culling due to infertility.

\section{Heritability}

Heritability estimates are shown in Table 1 for fertility traits and in Table 2 for linear type traits. All fertility traits had low heritability estimates, ranging from 0.02 to 0.04 .

The most heritable linear type traits were stature, rump width, rump angle, and BCS, which ranged from 0.29 to 0.39 . Conversely, the least heritable traits were

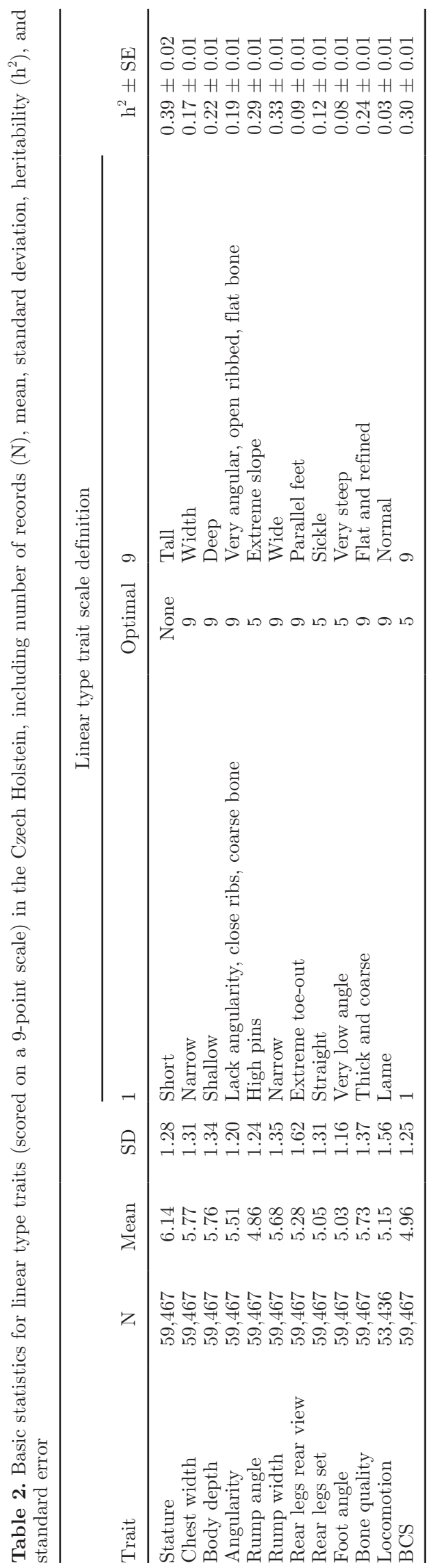


locomotion, foot angle, and rear legs rear view, which ranged from 0.03 to 0.09 .

\section{Estimated Genetic Correlations}

Genetic correlations among fertility and the linear type traits and their standard errors are presented in Table 3. Estimates ranged from -0.51 between BCS and CF2 to 0.44 between angularity and CF2. The largest negative genetic correlations were between BCS and fertility traits, except FL in second lactation (FL2), suggesting that BCS may be useful in selection programs that aim to improve fertility. The same trend, though positive, was shown for locomotion traits, except for FL in first lactation (FL1). The largest negative correlation with locomotion was -0.34 , for $\mathrm{CF}$ in first lactation (CF1) and second lactation (CF2), and this supports the idea of using locomotion score in a selection program. However, the heritability of this trait is low. An estimated genetic correlation of -0.19 was observed between chest width and CF1, and for the same trait, a moderate positive correlation of 0.34 with FL2 was found. Moderately high genetic correlations were observed for stature, body depth, angularity, rear legs set, and foot angle, whereas genetic correlations between rump width, rump angle, rear legs rear view, and fertility traits were mostly near zero.

\section{DISCUSSION}

\section{Heritability}

All fertility traits had heritability estimates that were near zero and low compared with other studies published in the literature (e.g., Veerkamp et al., 2001; Jamrozik et al., 2005), which support the hypothesis that fertility traits are difficult to use directly as selection criteria. For this reason, it may be necessary to select for improved fertility through other traits that are highly correlated with reproduction traits but are more highly heritable.

One potential selection target could be BCS, because the estimated heritability in this study was 0.30 , which is in agreement with other studies (Pryce et al., 2000; Royal et al., 2002). Some authors reported lower heritability for BCS (Lassen et al., 2003; Kadarmideen and Wegmann, 2003). Dal Zotto et al. (2007) estimated heritability of BCS in an Italian Brown Swiss population at 0.15 . A similar heritability of 0.13 was reported in the work of Bastin et al. (2010a) in Canadian Ayrshires and Holsteins. The authors attributed these lower heritability estimates to high variability between herds and BCS evaluators. In contrast, our study shows relatively high heritability, which provides an opportunity for selection.

In general, heritability estimates for other linear type traits in this study were close to estimates from earlier studies. The main differences were found for feet and legs traits. The heritability of locomotion in the present study was very low. Laursen et al. (2009) found a heritability of 0.09 , which is more in line with previous literature estimates. In addition, the study of Onyiro et al. (2008) estimated heritability of locomotion as 0.11. An estimated heritability close to zero for foot angle in our study differed from that of Onyiro et al. (2008) and Laursen et al. (2009) who reported estimates of 0.11 and 0.13 for this trait, respectively. Results for rear legs set were similar to those of Kadarmideen and Wegmann (2003), Dal Zotto et al. (2007), and Onyiro and Brotherstone (2008). In general, heritability estimates for feet and leg traits were lower in this study than in the previous literature.

\section{Genetic Correlations}

In this study, substantial differences existed between the data available from first and second lactations. This was caused largely by high culling rates in Czech Hol-

Table 3. Genetic correlations and their standard errors between fertility traits and linear type traits ${ }^{1}$

\begin{tabular}{|c|c|c|c|c|c|c|}
\hline Trait & $\mathrm{CF} 1$ & DO1 & FL1 & CF2 & DO2 & FL2 \\
\hline Chest width & $-0.19 \pm 0.07$ & $-0.05 \pm 0.08$ & $0.06 \pm 0.10$ & $-0.17 \pm 0.10$ & $0.21 \pm 0.13$ & $0.34 \pm 0.15$ \\
\hline Body depth & $-0.07 \pm 0.07$ & $0.14 \pm 0.08$ & $0.23 \pm 0.10$ & $0.04 \pm 0.10$ & $0.37 \pm 0.12$ & $0.43 \pm 0.16$ \\
\hline Rump angle & $0.02 \pm 0.06$ & $0.08 \pm 0.07$ & $0.07 \pm 0.10$ & $0.01 \pm 0.09$ & $-0.14 \pm 0.13$ & $-0.15 \pm 0.15$ \\
\hline Rump width & $-0.004 \pm 0.06$ & $0.07 \pm 0.07$ & $0.09 \pm 0.10$ & $0.02 \pm 0.09$ & $0.02 \pm 0.12$ & $-0.10 \pm 0.15$ \\
\hline Rear legs rear view & $-0.006 \pm 0.08$ & $0.12 \pm 0.09$ & $0.16 \pm 0.12$ & $-0.04 \pm 0.11$ & $0.0005 \pm 0.14$ & $0.04 \pm 0.18$ \\
\hline Bone quality & $0.17 \pm 0.06$ & $0.10 \pm 0.07$ & $-0.02 \pm 0.10$ & $0.16 \pm 0.10$ & $0.03 \pm 0.12$ & $-0.08 \pm 0.15$ \\
\hline Locomotion & $-0.34 \pm 0.09$ & $-0.10 \pm 0.11$ & $0.20 \pm 0.15$ & $-0.34 \pm 0.14$ & $-0.16 \pm 0.18$ & $0.09 \pm 0.22$ \\
\hline BCS & $-0.45 \pm 0.06$ & $-0.46 \pm 0.06$ & $-0.30 \pm 0.10$ & $-0.51 \pm 0.09$ & $-0.31 \pm 0.12$ & $0.02 \pm 0.15$ \\
\hline
\end{tabular}

${ }^{1} \mathrm{CF}=$ days from calving to first insemination; $\mathrm{DO}=$ days open; $\mathrm{FL}=$ days from first to last insemination; 1 refers to first parity and 2 refers to second parity. 
steins, which are mainly due to reproductive disorders or low production (Czech-Moravian Breeders Corporation, 2010; http://www.cmsch.cz/store/vysledky-ku2009-2010-metoda-a4-at-a.pdf).

\section{Relationships Between BCS and Fertility Traits}

Strong and desirable negative genetic correlations were estimated between BCS and all fertility traits, except FL2, presumably due to a small number of observations for FL2 as compared with other fertility traits. A strong negative genetic correlation $(-0.30)$ between BCS and DO was found by Dechow et al. (2004), which is consistent with our results for DO in second lactation (DO2; -0.31). A negative correlation between BCS and DO in first lactation (DO1) of -0.46 was reported by Veerkamp et al. (2001), who also reported genetic correlation between BCS and CF of -0.59 , which is similar to our result $(-0.45)$. Bastin et al. (2010b) reported that cows with genetically high BCS across lactations would have a greater chance of calf survival. Our results suggest that it would be optimal to have a cow with relatively high BCS. Strong unfavorable genetic correlations between BCS and angularity have been reported in some studies (Lassen et al., 2003). Moderate and low unfavorable genetic correlations were found between stature and fertility, although this indicates that large, angular cows have a higher risk of poor reproductive performance, which can be accompanied by low BCS.

\section{Relationships Between Locomotion, Feet, and Leg Traits and Fertility Traits}

Locomotion and rear legs rear view were indicated by Laursen et al. (2009) as traits related to claw health. Cows that have higher lameness scores on a 5 -point scale ( 1 = normal, $5=$ extremely lame) have a higher risk of culling and poorer reproductive performance (Bicalho et al., 2007). In the present study, a genetic correlation of -0.34 between locomotion and CF1 and CF2 was found. This suggests that locomotion can influence fertility and suggests the possibility of using this trait for selection. On the other hand, a very low heritability (0.03) was found for this trait in the present study. A higher heritability estimate (0.11) was published in the study by Onyiro and Brotherstone (2008) but overall, the heritability of this trait may not be high enough to use effectively in a selection program. Rear leg set had a strong positive genetic correlation with CF1, DO1, and $\mathrm{CF} 2$, which suggests that cows with sickled rear legs have shorter DO and FL. This result does not agree with the findings of Onyiro et al. (2008), who reported low negative correlations of -0.09 with calving interval (CI) and -0.11 with 56-d nonreturn rate. However, it is rather difficult to interpret these correlations, because rear leg set has an intermediate optimum. The large negative genetic correlation between locomotion and CF1 and CF2 shows clearly that cows with excellent locomotion have better reproduction. Also, in the present study, cows with steeper foot angle had fewer FL1 and short DO2. Therefore, it appears that cows with normal locomotion and steeper foot angle have better reproduction, and it is possible that some cows of this type could have moderately sickled rear leg set. No statistically significant results were found for rear legs rear view.

\section{Relationships Between Other Linear Type Traits and Fertility Traits}

Several studies have estimated genetic correlation between CI and linear type traits in Holstein cattle (e.g., Pryce et al., 2000; Onyiro et al., 2008) and in Brown Swiss (Dal Zotto et al., 2007). It is possible to compare results between studies of CI and DO, because González-Recio and Alenda (2005) found a very strong genetic correlation between these traits (0.99), as well as strong genetic correlations between CI and FL (0.98) and DO and FL (0.99).

Bone quality is evaluated as the thick and course of bones of the rear legs, and usually cows with greater bone quality evaluation are predisposed to more dairy character. Despite this, the study of Onyiro et al. (2008) reported that those cows that had flatter and more refined bones had better conception rates. In our study, the strongest relationship with bone quality was observed for CF1 (0.17). Strong genetic relationships were observed between some reproduction traits and chest width, body depth, and angularity. The strongest genetic correlations were for angularity, where statistically significant results ranged from 0.22 with FL1 to 0.44 with CF2. In first lactation, CF1 was favorably correlated with chest width $(-0.19)$, and it was unfavorably correlated with FL2 (0.34) in second lactation. This could be caused by differences of the body development between first and second lactation, or by selection bias. Similar results between CI and chest width and angularity were found by Pryce et al. (2000). They published a genetic correlation between CI and chest width of 0.28 , compared with our result of -0.19 for CF1. Again, this difference may be due to selection of animals after first lactation.

Speculation has occurred about the influence of rump traits on fertility. We found no significant results involving rump traits in the present study. A tendency toward a favorable relationship was observed between rump angle and DO2 (-0.14) and between rump angle and CF2 $(-0.15)$, but due to large standard errors $(0.13$ 
and 0.15 , respectively) these results were not significant. Other genetic correlations with rump traits were near zero. A statistical significant genetic correlation between CI and rump angle (-0.16) was published by Wall et al. (2005). With regard to rump width, Pryce et al. (2000) and Wall et al. (2005) reported genetic correlations near zero, which agreed with the present study. From these studies, it seems that no clear link between rump traits and fertility exists; hence, they would provide very little information when selecting for reproduction traits.

\section{CONCLUSIONS}

Genetic parameters between the linear type traits in this study and 3 fertility traits measured in first and in second lactation were estimated. Estimated genetic parameters show very low heritabilities for fertility traits. Moderate genetic correlations between some linear type traits and fertility traits were observed. The main focus was on locomotion and BCS, and the results of this study suggest that indirect selection for improved locomotion and higher BCS could improve reproductive performance in high-producing dairy herds. Above all, we observed strong and desirable negative genetic correlations between many fertility traits and BCS. The highest genetic correlation was -0.51 between BCS and CF2. However, genetic correlations with other production and fitness traits should be estimated before adding locomotion and BCS to a selection index. Despite the relatively low heritability of many fertility traits, an opportunity exists to improve reproductive performance through selection for a combination of interrelated traits.

\section{ACKNOWLEDGMENTS}

We gratefully acknowledge Kent A. Weigel (University of Wisconsin-Madison) for his help with the final manuscript. The authors also thank the CzechMoravian Breeders Corporation for providing data, and Line Hjortø Buch of the Danish Institute of Agricultural Sciences (Aarhus University, Tjele, Denmark), Luděk Bartoň, Jitka Matějíčková, and Mojmír Vacek (Institute of Animal Science, Prague, Czech Republic) for their helpful advice. This research was supported by projects NAZV QH91270 and MZE0002701404.

\section{REFERENCES}

Bastin, C., S. Loker, N. Gengler, A. Sewalem, and F. Miglior. 2010a. Genetic relationships between body condition score and reproduction traits in Canadian Holstein and Ayrshire first-parity cows. J. Dairy Sci. 93:2215-2228.

Bastin, C., S. Loker, N. Gengler, A. Sewalem, and F. Miglior. 2010b. Genetic relationship between calving traits and body condition score before and after calving in Canadian Ayrshire second-parity cows. J. Dairy Sci. 93:4398-4403.

Bicalho, R. C., F. Vokey, H. N. Erb, and C. L. Guard. 2007. Visual locomotion scoring in the first seventy days in milk: Impact on pregnancy and survival. J. Dairy Sci. 90:4586-4591.

Collard, B. L., P. J. Boettcher, J. C. M. Dekkers, D. Petitclerc, and L. R. Schaeffer. 2000. Relationships between energy balance and health traits of dairy cattle in early lactation. J. Dairy Sci. 83:2683-2690.

Czech-Moravian Breeders Corporation. 2010. Milk recording results from October 2009 to September 2010, Accessed Jun. 1, 2011. http://www.cmsch.cz/store/vysledky-ku-2009-2010-metoda-a4-ata.pdf.

Dal Zotto, R., M. De Marchi, C. Dalvit, M. Cassandro, L. Gallo, P. Carnier, and G. Bittante. 2007. Heritabilities and genetic correlations of body condition score and calving interval with yield, somatic cell score, and linear type traits in Brown Swiss cattle. J. Dairy Sci. 90:5737-5743.

Dechow, C. D., G. W. Rogers, and J. S. Clay. 2002. Heritability and correlations among body condition score loss, body condition score, production and reproductive performance. J. Dairy Sci. 85:3062-3070.

Dechow, C. D., G. W. Rogers, L. Klei, T. J. Lawlor, and P. M. VanRaden. 2004. Body condition scores and dairy form evaluations as indicators of days open in US Holsteins. J. Dairy Sci. 87:35343541.

Edmonson, A. J., I. J. Lean, L. D. Weaver, T. Farver, and G. Webster. 1989. A body condition scoring chart for Holstein dairy cows. J. Dairy Sci. 72:68-78.

González-Recio, O., and R. Alenda. 2005. Genetic parameters for female fertility traits and a fertility index in Spanish dairy cattle. J. Dairy Sci. 88:3282-3289.

Holtsmark, M., B. Heringstad, P. Madsen, and J. Ødegård. 2008. Genetic relationship between culling, milk production, fertility, and health traits in Norwegian Red cows. J. Dairy Sci. 91:4006-4012.

Jamrozik, J., J. Fatehi, G. J. Kistemaker, and L. R. Schaeffer. 2005. Estimates of genetic parameters for Canadian Holstein female reproduction traits. J. Dairy Sci. 88:2199-2208.

Jensen, J., E. A. Mäntysaari, P. Madsen, and R. Thompson. 1997. Residual maximum likelihood estimation of (co)variance components in multivariate mixed linear models using average information. J. Ind. Soc. Agric. Statist. 49:215-236.

Kadarmideen, H. N., and S. Wegmann. 2003. Genetic parameters for body condition score and its relationship with type and production traits in Swiss Holsteins. J. Dairy Sci. 86:3685-3693.

Lassen, J., M. Hansen, M. K. Sørensen, G. P. Aamand, L. G. Christensen, and P. Madsen. 2003. Genetic relationship between body condition score, dairy character, mastitis, and diseases other than mastitis in first-parity Danish Holstein cows. J. Dairy Sci. $86: 3730-3735$.

Laursen, M. V., D. Boelling, and T. Mark. 2009. Genetic parameters for claw and leg health, foot and leg conformation, and locomotion in Danish Holsteins. J. Dairy Sci. 92:1770-1777.

Madsen, P., and J. Jensen. 2008. An user's guide to DMU: A package for analysing multivariate mixed models. Version 6 , release 4.7. Aarhus University, Foulum, Denmark. Accessed June 1, 2011. http://dmu.agrsci.dk/ dmuv6_guide-R4-6-7.pdf.

Oikonomou, G., G. Arsenos, G. E. Valergakis, A. Tsiaras, D. Zygoyiannis, and G. Banos. 2008. Genetic relationship of body energy and blood metabolites with reproduction in Holstein cows. J. Dairy Sci. 91:4323-4332.

Onyiro, O. M., L. J. Andrews, and S. Brotherstone. 2008. Genetic parameters for digital dermatitis and correlations with locomotion, production, fertility traits, and longevity in Holstein-Friesian dairy cows. J. Dairy Sci. 91:4037-4046.

Onyiro, O. M., and S. Brotherstone. 2008. Genetic analysis of locomotion and associated conformation traits of Holstein-Friesian dairy cows managed in different housing systems. J. Dairy Sci. 91:322-328.

Pérez-Cabal, M. A., C. García, O. González-Recio, and R. Alenda. 2006. Genetic and phenotypic relationships among locomotion 
type traits, profit, production, longevity, and fertility in Spanish dairy cows. J. Dairy Sci. 89:1776-1783.

Pryce, J. E., M. P. Coffey, and S. Brotherstone. 2000. The Genetic relationship between calving interval, body condition score and linear type and management traits in registered Holsteins. J. Dairy Sci. 83:2664-2671.

Roche, J. R., N. C. Friggens, J. K. Kay, M. W. Fisher, K. J. Stafford, and D. P. Berry. 2009. Invited review: Body condition score and its association with dairy cow productivity, health, and welfare. J. Dairy Sci. 92:5769-5801.

Royal, M. D., J. E. Pryce, J. A. Woolliams, and A. P. F. Flint. 2002. The genetic relationship between commencement of luteal activity and calving interval, body condition score, production, and linear type traits in Holstein-Friesian dairy cattle. J. Dairy Sci. 85:3071-3080
Sewalem, A., G. J. Kistemaker, and B. J. Van Doormaal. 2005. Relationship between type traits and longevity in Canadian Jerseys and Ayrshires using a Weibull proportional hazards model. J. Dairy Sci. 88:1552-1560.

Veerkamp, R. F., E. P. C. Koenen, and G. De Jong. 2001. Genetic correlations among body condition score, yield, and fertility in first-parity cows estimated by random regression models. J. Dairy Sci. 84:2327-2335.

Wall, E., I. M. S. White, M. P. Coffey, and S. Brotherstone. 2005. The relationship between fertility, rump angle, and selected type information in Holstein-Friesian cows. J. Dairy Sci. 88:1521-1528.

Windig, J. J., M. P. L. Calus, B. Beerda, and R. F. Veerkamp. 2006. Genetic correlations between milk production and health and fertility depending on herd environment. J. Dairy Sci. 89:1765-1775. 